\title{
Spatial and seasonal variability of Chlorophyll-a and associated oceanographic events in Sabah water
}

\begin{abstract}
This study investigated the spatial and temporal distributions of Chlorophyll-a (Chl-a) in Sabah coastal water using satellite data, and identified the associated oceanographic events which caused large scale water enrichment in the surface layer. Results showed that surface Chl-a experienced seasonality in Sabah waters. At the northwest coast, very obvious increase in the Chl-a was observed from January to March, attributed to wind-driven coastal upwelling during the northeast monsoon (NEM). The southeast coast depicted high Chl-a at Labuan offshore water, related to the reversing direction of Baram River plume towards Sabah during NEM. Labuan bay water had higher Chl-a during the southwest monsoon (SWM) due to the effect of discharged materials from the Padas River during the rainy season at Labuan. On the other side, a slight increase in surface Chl-a was illustrated along the entire northeast coast during NEM, with higher concentrations at the southern part compared to the northern region. The high Chl-a at the southern part (southern Sandakan) was owing to alongshore water transport from the northern region driven by NEM winds and effect of discharged materials from the Kinabatangan River during the rainy season at Sandakan. Water characteristic at the southeast coast was highly influenced by surface water transport from the Sulu and Sulawesi seas and prevailed surface currents. Both inshore and offshore waters off Semporna had peak Chl-a in December, related to Sulu Sea water transport towards Semporna and occurrence of cyclonic eddy at the offshore water during early NEM. Tawau water showed very high Chl-a throughout the year due to the effect of coastal discharge. The discharged material near Tawau was transported to a wider area offshore during SWM. That in turn caused another peak Chl-a at Semporna inshore water in August during SWM.
\end{abstract}

Keyword: Seasonal variation; Chlorophyll-a; Upwelling; Asian monsoon; Sabah water 